ESCOBAR, Javier. "Sujeto activo del delito de omisión de auxilio en accidentes de tránsito".

Polít. crim. Vol. 13, № 26 (Diciembre 2018) Art. 9, pp. 1003-1026.

[http://www.politicacriminal.cl/Vol_13/n_26/Vol13N26A9.pdf]

\title{
Sujeto activo del delito de omisión de auxilio en accidentes de tránsito*
}

\section{Obliged subject in the crime of omission of aid in traffic accidents}

\author{
Javier Escobar Veas \\ Doctorando en Derecho, Università Luigi Bocconi \\ Profesor de Derecho Penal, Universidad Mayor \\ javier.escobar@mail.udp.cl
}

\section{Resumen:}

El delito de omisión de auxilio en accidentes de tránsito, establecido en el artículo 195 de la Ley $\mathrm{N}^{\circ}$ 18.290, plantea diversos problemas dogmáticos, siendo uno de ellos determinar los específicos elementos que debe reunir el sujeto activo. Al respecto, tanto en Chile como a nivel comparado la opinión mayoritaria adscribe a una concepción meramente "causalista", exigiendo como único requisito que la persona obligada haya intervenido causalmente -de cualquier manera- en el accidente de tránsito. El presente trabajo tiene por finalidad analizar críticamente la tesis indicada, desarrollando las razones en virtud de las cuales, en el derecho chileno, ella debiese ser rechazada. El artículo propone una interpretación alternativa, conforme a la cual la mera causalidad no basta para efectos de configurar un sujeto activo idóneo en este delito, sino que, además, se requiere que los resultados lesivos ocasionados por el accidente, cuya conjuración se omite, sean imputables objetivamente a la conducta previa del agente.

Palabras clave: Omisión de auxilio en accidentes de tránsito, delitos de infracción de deber, obligado especial.

\begin{abstract}
:
The crime of omission of aid in traffic accidents, prescribed in article 195 of $\mathrm{Law}^{\circ}$ 18.290, presents diverse dogmatic problems, being one of them the requirements of the active subject. Regarding this matter, both from the perspective of Chilean law as well as comparative law, the majority supports a causalist conception, requiring only the obliged person to have causal intervention in the traffic accident. The present work reviews critically the mentioned thesis and indicates the reasons why, in the national context, it should be rejected. The article proposes an alternative interpretation, according to which the mere causality is not sufficient on its own. In addition, the injurious results caused by the accident must be objectively attributable to the author's previous conduct.
\end{abstract}

Key words: Omission of aid in traffic accidents, special offenses, obliged subject.

\footnotetext{
* Agradezco al profesor Alex van Weezel por las observaciones formuladas a una versión preliminar de este trabajo. Los errores que pudieren haber subsistido, por supuesto, son de mi exclusiva responsabilidad.
} 
Polit. crim. Vol. 13, № 26 (Diciembre 2018) Art. 9, pp. 1003-1026.

[http://www.politicacriminal.cl/Vol_13/n_26/Vol13N26A9.pdf]

\section{Introducción}

Con fecha 16 de septiembre de 2014 fue publicada la Ley $\mathrm{N}^{\circ} 20.770$, cuerpo normativo que introdujo diversas modificaciones a la Ley de Tránsito, $\mathrm{N}^{\circ} 18.290^{1}$. La intención original del proyecto de ley, señalada en el mensaje del Ejecutivo ${ }^{2}$, era hacerse cargo, a través del aumento de las penas, de la sensación de impunidad existente en la sociedad respecto al delito de manejo en estado de ebriedad con resultado de muerte o lesiones gravísimas (artículo $391 \mathrm{~N}^{\circ} 1$ del Código Penal) ${ }^{3}$.

No obstante, la nueva ley excedió las intenciones inicialmente perseguidas, estableciendo en definitiva otra clase de modificaciones ${ }^{4}$. Dos ejemplos de lo anterior fueron la incorporación del nuevo artículo 195 bis, el cual sanciona la negativa injustificada a someterse a pruebas científicas destinadas a detectar la presencia de sustancias prohibidas ${ }^{5}$, y la sustitución del artículo $195^{6}$, norma que prescribe la figura de omisión de auxilio en accidentes de tránsito ${ }^{7}$.

La nueva regulación del delito de omisión de auxilio plantea interesantes problemas dogmáticos. Uno de ellos consiste en determinar cuáles son los requisitos necesarios que debe reunir la persona sobre la cual recaerán los deberes indicados en la norma ("conductor obligado"). Al respecto, tanto en Chile como a nivel comparado es posible señalar que la postura mayoritaria adscribe a una concepción meramente "causal", exigiendo como único requisito, para efectos de configurar un sujeto activo idóneo, que el obligado especial haya contribuido con alguna condición causal a la producción del accidente.

El presente trabajo tiene por finalidad abordar la problemática del sujeto activo en el delito de omisión de auxilio en accidentes de tránsito. En la primera parte se expondrá la nueva

\footnotetext{
${ }^{1}$ En lo sucesivo, toda referencia normativa debe entenderse efectuada a este cuerpo legal, a menos que del contexto se infiera lo contrario.

2 Historia de la Ley $\mathrm{N}^{\circ}$ 20.770, Biblioteca del Congreso Nacional, p. 4. Disponible en: http://www.bcn.cl/historiadelaley/nc/historia-de-la-ley/4318/ [visitado el 10/06/2017].

${ }^{3}$ En opinión de Matus, esta sensación de impunidad se debía a que, en muchos casos, la aplicación de las disposiciones de la Ley de Tránsito, del Código Penal y de la Ley $\mathrm{N}^{\circ} 18.216$, sobre penas sustitutivas, desdibuja las diferenciaciones que, en abstracto, ha construido el legislador, generando como consecuencia que, ante hechos de gravedad, la sanción final sea sustancialmente diversa a la establecida, siendo en algunas situaciones similar a la impuesta "por los Juzgados de Policía Local respecto de la reiteración de infracciones de tránsito graves". MATUS, Jean Pierre, "Ley Emilia", Revista Doctrina y Jurisprudencia Penal, Año 5, edición especial, pp. 101-113, p. 102.

${ }^{4}$ FALCONE, Diego, "El delito de negativa injustificada de un conductor a someterse a los exámenes de detección de alcohol o sustancias estupefacientes o psicotrópicas", Revista de Derecho de la Pontifica Universidad Católica de Valparaíso, V. 46, $\mathrm{N}^{\circ}$ 1, pp. 143-169, p. 144, en: http://www.scielo.cl/pdf/rdpucv/n44/a05.pdf [visitado el 02/04/2017].

${ }^{5}$ FALCONE, "El delito de negativa", cit. nota $N^{\circ} 4$, p. 144.

${ }^{6}$ La nueva ley incorporó, además, normas especiales sobre determinación y sustitución de penas. MATUS, Jean Pierre; RAMÍREZ, María Cecilia, Manual de Derecho Penal Chileno, Parte Especial, Valencia: Tirant lo Blanch, 2017, pp. 220 y 221.

${ }^{7} \mathrm{Si}$ bien la conducta sancionada no consiste únicamente en omitir el auxilio debido, e incluso en un caso ni siquiera lo requiere (inciso primero), en el presente trabajo se utilizará esta denominación para efectos de simplificar su referencia.
} 
ESCOBAR, Javier. "Sujeto activo del delito de omisión de auxilio en accidentes de tránsito".

regulación del ilícito en estudio y se describirá el planteamiento de la tesis causalista, haciendo referencia a su recepción en Chile y en el derecho comparado. Luego, en una segunda parte, se revisarán críticamente los fundamentos de esta tesis, desarrollando los argumentos en virtud de los cuales, en el derecho chileno, debiese ser rechazada. Finalmente, en una tercera parte, se propone una interpretación alternativa a la hasta ahora vigente, conforme a la cual la mera causalidad no basta para efectos de apreciar un sujeto activo idóneo, sino que, además, los resultados lesivos ocasionados por el accidente, cuya conjuración se omite, deben ser imputables objetivamente a la conducta previa del agente.

\section{Nueva regulación del delito de omisión de auxilio y recepción de la tesis causalista en Chile. Referencia al derecho español e italiano}

La Ley $\mathrm{N}^{\circ} 20.770$ sustituyó íntegramente el texto del artículo 195, estableciendo la regulación actualmente vigente. En cuanto a los supuestos de incriminación y aplicación, la estructura del nuevo tipo penal puede resumirse de la siguiente forma:

a. Accidentes que sólo ocasionaron daños (artículo 195, inciso primero ${ }^{8}$ ): En estos casos, el conductor obligado únicamente deberá dar cuenta a la autoridad policial más próxima. La sanción en caso de incumplimiento es multa de tres a siete unidades tributarias mensuales y suspensión de la licencia de conducir hasta por un mes.

b. Accidentes que ocasionaron lesiones o muertes (artículo 195, incisos segundo 9 y tercero $^{10}$ ): En estos casos, el conductor obligado deberá detener su marcha, prestar la ayuda que fuese posible y dar cuenta a la autoridad policial más inmediata. La sanción en caso de incumplimiento dependerá de los resultados lesivos ocasionados por el accidente. Si éste ha provocado lesiones leves, menos graves o simplemente graves (artículos $494 \mathrm{~N}^{\circ}$ 5, 399 y $397 \mathrm{~N}^{\circ}$ 2, todos del Código Penal), las penas serán presidio menor en su grado medio, inhabilidad perpetua para conducir vehículos de tracción mecánica y multa de siete a diez unidades tributarias mensuales. Ahora, si el accidente ha ocasionado lesiones gravísimas o la muerte de alguna persona, las penas serán presidio menor en su grado máximo, inhabilidad perpetua para conducir vehículos de tracción mecánica, multa de once a veinte unidades tributarias mensuales y el comiso del vehículo.

\footnotetext{
8 “Artículo 195.- El incumplimiento de la obligación de dar cuenta a la autoridad de todo accidente en que sólo se produzcan daños, señalada en el artículo 168, será sancionado con multa de tres a siete unidades tributarias mensuales y con la suspensión de la licencia hasta por un mes".

9 "El incumplimiento de la obligación de detener la marcha, prestar la ayuda posible y dar cuenta a la autoridad de todo accidente en que se produzcan lesiones, señalada en el artículo 176, se sancionará con la pena de presidio menor en su grado medio, inhabilidad perpetua para conducir vehículos de tracción mecánica y multa de siete a diez unidades tributarias mensuales".

10 "Si en el caso previsto en el inciso anterior las lesiones producidas fuesen de las señaladas en el número $1^{\circ}$ del artículo 397 del Código Penal o se produjese la muerte de alguna persona, el responsable será castigado con la pena de presidio menor en su grado máximo, inhabilidad perpetua para conducir vehículos de tracción mecánica, multa de once a veinte unidades tributarias mensuales y con el comiso del vehículo con que se ha cometido el delito (...)".
} 


\section{Polit. crim. Vol. 13, No 26 (Diciembre 2018) Art. 9, pp. 1003-1026. \\ [http://www.politicacriminal.cl/Vol_13/n_26/Vol13N26A9.pdf]}

El nuevo tipo penal (omisión propia ${ }^{11}$ ) se erige como una hipótesis de delito especial, pues sólo puede ser considerado autor aquella persona en quien concurran los elementos, cualidades o relaciones exigidas por la ley ${ }^{12}$ (obligado especial ${ }^{13}$ ). En efecto, los deberes y obligaciones establecidos en el artículo 195 únicamente gravan al conductor que hubiere participado en el específico accidente de tránsito. Lo anterior pone de manifiesto la importancia de determinar quién es este "conductor obligado".

Al respecto, a nivel comparado la opinión mayoritaria adscribe a una tesis meramente causalista. Conforme a ésta, los deberes de auxilio y colaboración gravan a todo conductor, sin distinción alguna, que haya contribuido con alguna condición causal a la producción del accidente $^{14}$. Utilizando los términos de la teoría de la equivalencia de las condiciones ${ }^{15}$, basta con que el comportamiento del sujeto obligado haya constituido una conditio sine qua non del accidente, siendo irrelevantes todas aquellas consideraciones de índole valorativa ${ }^{16}$. El Tribunal Supremo español ha señalado, en este sentido, que carece de toda importancia la circunstancia de que la persona herida haya sido responsable por la producción del accidente, incluso si ella misma tuvo la voluntad de autolesionarse o de quitarse la vida ${ }^{17}$. Aun en estos casos el obligado especial debe cumplir con sus deberes de auxilio y colaboración $^{18}$.

En Chile, las opiniones existentes sobre la materia también han adscrito a un planteamiento causalista. En este contexto destaca, en primer lugar, la postura de van Weezel, quien, a propósito del antiguo texto del artículo 195, sostuvo que éste comprendía aquellos accidentes en que la conducción motorizada se había realizado dentro del riesgo permitido, estando igualmente obligados, los conductores involucrados, a detener la marcha y prestar

\footnotetext{
${ }^{11}$ MATUS; RAMÍREZ, Manual, cit. nota $\mathrm{N}^{\circ}$ 6, pp. 215 y ss. Sobre el concepto de omisión propia, ver ROXIN, Claus, Derecho Penal, Parte General, T. II, Trad. LUZÓN PEÑA, Diego-Manuel; PAREDES CASTAÑON, José Manuel; DÍAZ Y GARCÍA CONLLEDO, Miguel; DE VICENTE REMESAL, Javier, Madrid: Thomson Reuters-Civitas, 2014, p. 759.

12 MARINUCCI, Giorgio; DOLCINI, Emilio, Manuale di Diritto Penale, Parte Generale, $6^{\circ}$ edizione, Milano: Giuffrè, 2017, pp. 232 y 233; GÓMEZ, Víctor, "Delitos de posición y delitos con elementos meramente tipificadores. Nuevas bases para una distinción necesaria”, Revista Electrónica de Ciencia Penal y Criminología, Año 2012, N 14, pp. 1-29, p. 1, en: http://criminet.ugr.es/recpc/14/recpc14-01.pdf [visitado el 15/12/2017]; ROXIN, Claus, Derecho Penal, Parte General, T. I, Trad. LUZÓN PEÑA, Diego-Manuel; DÍAZ Y GARCÍA CONLLEDO, Miguel; DE VICENTE REMESAL, Javier, Madrid: Civitas, 1997, p. 338.

13 OSSANDON, Magdalena, "Delitos especiales y de infracción de deber en el Anteproyecto de Código Penal", en Política Criminal, Año 2006, A. 4, pp. 1-22, 6-7, en: http://www.politicacriminal.cl/n_01/pdf_01/a_4.pdf [visitado el 02/01/2018].

${ }^{14}$ BASILE, Enrico, “Articolo 189. Comportamento in caso di incidente”, en: DOLCINI, Emilio y GATTA, Gian Luigi (directores), Codice Penale Commentato, T. III, $4^{\circ}$ edizione, Milano: Wolters Kluwer, 2015, pp. 2551-2564, p. 2555; MOLINA, Concepción, "El artículo 195.3 del código penal de 1995; problemas de aplicación”, Revista de Derecho Penal y Criminología, Año 1999, № 4, pp. 555-580, p. 578.

${ }^{15}$ MARINUCCI; DOLCINI, Manuale, cit. nota N ${ }^{\circ}$ 13, pp. 220 a 222; ROXIN, Claus, Derecho Penal, T. I, cit. nota $\mathrm{N}^{\circ} 12$, pp. 347 y ss.

${ }^{16}$ BASILE, “Articolo 189”, cit. nota $\mathrm{N}^{\circ} 14$, p. 2555.

${ }^{17}$ Sentencia Roj 5.162/1989, de fecha 06 de octubre de 1989.

${ }^{18}$ En el mismo sentido, la Corte Suprema di Cassazione italiana, sezione penale IV, sentencia $\mathrm{N}^{\circ} 15.040-$ 2014.
} 
ESCOBAR, Javier. "Sujeto activo del delito de omisión de auxilio en accidentes de tránsito".

auxilio $^{19}$. En el caso de Matus y Ramírez, si bien los autores no abordan explícitamente la materia en estudio, el hecho que califiquen los resultados lesivos ocasionados por el accidente como condiciones objetivas de punibilidad, y consideren el delito en estudio como una figura especial de omisión de socorro, permite inferir que, desde su punto de vista, el tipo penal no contempla exigencias de naturaleza valorativa entre la conducta previa del conductor y las consecuencias lesivas provocadas ${ }^{20}$.

En el mismo sentido se ha pronunciado la jurisprudencia de la Corte Suprema, afirmando que el delito de omisión de auxilio no contempla, dentro de sus requisitos, que el conductor obligado haya sido responsable del accidente. En su opinión, las obligaciones contenidas en el artículo 195 "tienen como destinatarios a todos quienes formen parte de un accidente como conductores", con independencia de sus particulares responsabilidades ${ }^{21}$.

Con la finalidad de exponer los planteamientos y el desarrollo de la teoría causalista a nivel comparado, a continuación se revisará el derecho italiano y español.

\subsection{La regulación italiana: Omissione di soccorso stradale}

El legislador italiano ha establecido, igual que en el caso chileno, delitos especiales para sancionar el incumplimiento de deberes de auxilio y colaboración en casos de accidentes de tránsito. Así, el artículo 189 del Codice della Strada contempla, en sus números 5, 6 y 7, tres figuras típicas ordenadas de manera ascendente según su gravedad ${ }^{22}$. El sistema establecido por los tres apartados puede resumirse de la siguiente manera:

a. El número 5 sanciona al utente della strada ${ }^{23}$ que incumpla la obligación de detener la marcha en accidentes que únicamente hubieren provocado daños. La sanción en este caso es multa de 294 a 1.174 euros y, si los daños fueron graves, suspensión de la licencia de conducir de quince días a dos meses.

b. El número 6, por su parte, sanciona al utente della strada que no cumpla con la obligación de detener la marcha en accidentes donde se hubieren provocado lesiones. La sanción establecida es reclusión de seis meses a tres años y suspensión de la licencia de conducir de uno a tres años.

c. Finalmente, el número 7 sanciona al utente della strada que incumpla la obligación de auxiliar a las personas que hubieren resultado lesionadas a causa del accidente. La sanción en este caso es reclusión de uno a tres años y suspensión de la licencia de conducir de un año y seis meses a cinco años.

\footnotetext{
${ }^{19}$ VAN WEEZEL, Alex, "Solidaridad en el tráfico motorizado. El delito de omisión de auxilio en caso de accidente”, Revista Doctrina y Jurisprudencia Penal, Año 5, edición especial, pp. 191-204, p. 194.

${ }^{20}$ MATUS; RAMÍREZ, Manual, cit. nota № 6, p. 220.

${ }^{21}$ Sentencia Rol 35.715-2017.

${ }^{22}$ BASILE, “Articolo 189”, cit. nota N 14, pp. 2553 y 2554.

${ }^{23}$ Al tratarse de un concepto jurídico, se ha decidido utilizar la expresión original ("utente della strada") y no su traducción, pues ésta no sería de utilidad.
} 


\section{Polit. crim. Vol. 13, № 26 (Diciembre 2018) Art. 9, pp. 1003-1026. \\ [http://www.politicacriminal.cl/Vol_13/n_26/Vol13N26A9.pdf]}

Sobre el bien jurídico protegido en los distintos ilícitos, la doctrina distingue entre las hipótesis de fuga (números 5 y 6) y la de omisión de auxilio (número 7). En el primer caso el interés tutelado sería la correcta administración de justicia, mientras que en el segundo la vida e integridad de la persona herida ${ }^{24}$. En este sentido, tanto doctrina ${ }^{25}$ como jurisprudencia ${ }^{26}$ sostienen que el delito de omisión de auxilio constituye una figura especial en relación al tipo de omisión de socorro, contemplado en el artículo 593 del Código Penal. Los elementos específicos serían los sujetos, tanto activo (utente della strada) como pasivo (la persona lesionada por el accidente), y un determinado antecedente fáctico (el accidente de tránsito).

Respecto al sujeto activo de las distintas figuras contempladas en el artículo 189, cabe primero resolver cuál el sentido que debe atribuirse a la expresión "utente della strada", destinatario de los mandatos establecidos en la norma citada. Sobre lo anterior, existe consenso en que tal expresión no está circunscrita al conductor de un vehículo motorizado, sino que hace referencia a todos aquellos que utilicen la "strada" conforme a su destinación, incluyéndose, de esta forma, conductores de vehículos no motorizados, pasajeros y peatones $^{27}$.

Ahora, en relación con los elementos que debe reunir esta persona para configurar un sujeto activo idóneo, la opinión unánime adscribe a un planteamiento causalista. El argumento principal es el significado y alcance de la expresión "comunque ricollegabile al suo comportamento" ("de cualquier manera relacionada con su comportamiento"), contenida en el número 1 del artículo $189^{28}$. La jurisprudencia permanente de la Corte Suprema di Cassazione ha señalado que la citada expresión descarta cualquier posible exigencia de índole valorativa, constituyendo un requisito meramente causal, cuya finalidad es identificar a los sujetos sobre los cuales recaerán las obligaciones de detener la marcha y prestar auxilio, no siendo en absoluta necesario que el imputado haya sido "responsable" por el accidente provocado ${ }^{29}$.

\footnotetext{
${ }^{24}$ BASILE, “Articolo 189”, cit. nota $\mathrm{N}^{\circ}$ 14, p. 2554; Corte Suprema di Cassazione, sezione penale IV, sentencia $\mathrm{N}^{\circ}$ 42.308-2017.

25 CARINGELlA, Francesco; DE PALMA, Michele; FARINI, Sara; TRINCI, Alessandro, Manuale di Diritto Penale, Parte Speciale, 6 edizione, Roma: Dike Giuridica, 2016, p. 968; BASILE, “Articolo 189”, cit. nota $\mathrm{N}^{\circ}$ 14, p. 2554; BALZANI, Simone; TRINCI, Alessandro, I reati in materia di circolazione stradale, Milano: Wolters Kluwer, 2016, p. 400; MANTOVANI, Ferrando, Diritto Penale, Parte Speciale, $6^{\circ}$ edizione, Milano: Wolters Kluwer, 2016, p. 205

${ }^{26}$ Corte Suprema di Cassazione, sezione penale IV, sentencias Nº 9.128-2012, 20.649-2012 y 15.040-2014.

${ }^{27}$ BALZANI; TRINCI, I reati, cit. nota $\mathrm{N}^{\circ} 25$, p. 202; BASILE, “Articolo 189”, cit. nota N 14 , pp. 2554 y 2555; CARINGELLA; DE PALMA; FARINI; TRINCI, Manuale di Diritto Penale, cit. nota N ${ }^{\circ} 25$, p. 968. Esta concepción extensiva, además, encuentra respaldo expreso en el artículo 3, número 53-bis, del Codice della Strada, norma que, al definir la expresión "utente debole della strada", incluye a los peatones y ciclistas, entre otros.

28 "Art. 189. Comportamento in caso di incidente.

1. L'utente della strada, in caso di incidente comunque ricollegabile al suo comportamento, ha l'obbligo di fermarsi e di prestare l'assistenza occorrente a coloro che, eventualmente, abbiano subito danno alla persona".

${ }^{29}$ Corte Suprema di Cassazione, sezione penale IV, sentencias $\mathrm{N}^{\circ} \mathrm{s} 1.276-2014,34.138-2011,15.040-2014 \mathrm{y}$ 52.539-2017. En el mismo sentido, BASILE, “Articolo 189”, cit. nota N 14, p. 2555.
} 
ESCOBAR, Javier. "Sujeto activo del delito de omisión de auxilio en accidentes de tránsito".

En conclusión, es posible señalar que la postura unánime en Italia adscribe, por razones de texto expreso, a una postura causalista, conforme a la cual la única condición para exigir el cumplimiento de los mandatos indicados radica en la generalísima relación (a cualquier título) entre el incidente y el comportamiento del "utente della strada"

\subsection{La situación en España: Aplicación del tipo general de omisión de socorro}

En materia de omisión de auxilio en accidentes de tránsito, cabe destacar que el legislador español, a diferencia del italiano y el chileno, ha decidido prescindir de figuras especiales, aplicando en cambio el sistema general de la omisión de socorro ${ }^{31}$, delito contenido en el artículo 195 del Código Penal. En sus dos primeros números esta norma contempla un tipo básico de omisión de socorro (con dos modalidades), mientras que en el tercero establece una figura agravada en razón del comportamiento previo del obligado, disponiendo la aplicación de una pena superior cuando la víctima lo fuere por accidente ocasionado fortuita o imprudentemente por el que omitió el auxilio ${ }^{32}$.

Con anterioridad a la entrada en vigencia del Código Penal de 1995, la hipótesis calificada no señalaba explícitamente si el "accidente" podía tener como origen una conducta dolosa, culposa o fortuita del imputado $^{33}$. Al respecto surgieron tres teorías ${ }^{34}$ :

a. Una primera línea afirmaba que el vocablo "accidente" se refería únicamente a sucesos fortuitos $^{35}$. Si concurriese dolo o culpa en el actuar previo del agente, la omisión de auxilio ulterior por parte de éste constituiría una omisión comisiva del delito de resultado provocado.

b. Un segundo grupo postulaba, en cambio, que el término "accidente" debía interpretarse en el sentido de una intervención imprudente por parte del imputado. Solo tal interpretación permitiría fundamentar la mayor sanción prevista por la norma ${ }^{36}$.

\footnotetext{
${ }^{30}$ Corte Suprema di Cassazione, sezione penale IV, sentencia $\mathrm{N}^{\circ} 33.761-2017$.

31 TORÍO, Ángel, "Aspectos de la omisión especial de socorro", Anuario de Derecho Penal y Ciencias Penales, Año 1967, $\quad \mathrm{N}^{\circ}$ 1-2, pp. 581-602, pp. $581 \quad$ a 584 , en: https://www.boe.es/publicaciones/anuarios_derecho/anuario.php?id=P_1967_ANUARIO_DE_DERECHO_P ENAL_Y_CIENCIAS_PENALES [visitado el 12/04/2017].

32 FARALDO, Patricia, "Omisión del deber de socorro. Especial referencia a la negativa al tratamiento médico”, en: SANZ, Francisco y GÓMEZ, José María (directores), Lecciones de Derecho Sanitario, Coruña: Universidade da Coruña, 1999, pp. 519-554, p. 530; MUÑOZ CONDE, Francisco, Derecho Penal, Parte Especial, $15^{\circ}$ edición, Valencia: Tirant lo Blanch, 2004, pp. 335 y 336. La norma citada dispone: "3. Si la víctima lo fuere por accidente ocasionado fortuitamente por el que omitió el auxilio, la pena será de prisión de seis meses a 18 meses, y si el accidente se debiere a imprudencia, la de prisión de seis meses a cuatro años".

${ }^{33}$ GÓMEZ, Víctor, "Omisión del deber de socorro, comisión por omisión y seguridad en el tráfico", en: MIR, Santiago (director) y CARDENAL, Sergi (coordinador), Seguridad vial y Derecho penal, Valencia: Tirant lo Blanch, 2008, pp. 283-322, p. 296.

34 DOPICO, Jacobo, "Omisión de socorro tras accidente fortuito. La imputación de sucesos lesivos a conductas licitas", Anuario de Derecho Penal y Ciencias Penales, Año 2002, pp. 235-284, pp. 236 y 237, en: https://www.boe.es/publicaciones/anuarios_derecho/anuario.php?id=P_2002_ANUARIO_DE_DERECHO_P ENAL_Y_CIENCIAS_PENALES [visitado el 20/12/2017].

${ }^{35}$ TORÍO, "Aspectos de la omisión”, cit. nota $N^{\circ} 31$, p.581.

${ }^{36}$ DOPICO, Jacobo, “Omisión de socorro”, cit. nota $\mathrm{N}^{\circ} 34$, p. 237.
} 
Polit. crim. Vol. 13, № 26 (Diciembre 2018) Art. 9, pp. 1003-1026.

[http://www.politicacriminal.cl/Vol_13/n_26/Vol13N26A9.pdf]

c. Finalmente, una tercera postura señalaba que el término "accidente" abarcaba tanto los sucesos imprudentes como fortuitos ${ }^{37}$. En caso de que la causa del accidente fuere un actuar imprudente del imputado, éste sería sancionado por el respectivo delito culposo en concurso con la figura agravada de omisión de socorro ${ }^{38}$.

En cuanto a la jurisprudencia española, ésta adscribió a un planteamiento causalista, incorporando dentro del concepto "accidente" aquellos sucesos fortuitos. Así, el Tribunal Supremo sostuvo que la única exigencia respecto al sujeto activo de esta figura agravada era que su conducta previa se encontrase en una relación de causalidad con el suceso lesivo, descartándose consideraciones de naturaleza valorativa ${ }^{39}$.

Con la entrada en vigencia del Código Penal de 1995, el legislador español resolvió la anterior discusión, señalando explícitamente que el origen del accidente puede ser fortuito o imprudente $^{40}$. Asimismo, excluyó de la hipótesis agravada los accidentes dolosos, supuestos en los cuales el autor responderá únicamente por el ilícito cometido y no por la posterior omisión de socorro ${ }^{41}$.

\section{Revisión crítica de los fundamentos de la tesis causalista}

Habiendo ya descrito el planteamiento causalista, en esta segunda parte se analizarán críticamente sus dos principales fundamentos: 1. El significado de la expresión "accidente"; y 2. La solidaridad como bien jurídico protegido o como fundamento normativo de la incriminación.

\subsection{Significado de la expresión "accidente"}

\footnotetext{
${ }^{37}$ SILVA SÁNCHEZ, Jesús María, "Problemas del tipo de omisión del deber de socorro (Comentario a la STS de 27 de abril de 1987)", Anuario de Derecho Penal y Ciencias Penales, Año 1987, N², pp. 561-574, pp. 571 y ss., en: https://www.boe.es/publicaciones/anuarios_derecho/abrir_pdf.php?id=ANU-P-198820056100574_ANUARIO_DE_DERECHO_PENAL_Y_CIENCIAS_PENALES_Comentarios_a_la_jurispru dencia_del_Tribunal_Supremo,_Secci\%F3n_dirigida_por_Santiago_Mir_Puig:_Problemas_del_tipo_de_omis i\%F3n_del_deber_de_socorro_(Comentario_a_la_STS_de_27_de_abril_de_1987,_ponente_Sr._Diaz_Palos) [visitado el 22/04/2017].

38 BUSTOS, Juan, Manual de Derecho penal, Parte especial, $2^{\circ}$ edición, Barcelona: Ariel, 1991, p. 85; GÓMEZ, "Omisión del deber de socorro", cit. nota N 33, p. 296.

${ }^{39}$ Sentencia Roj 5.162/1989, de fecha 06 de octubre de 1989.

40 MUÑOZ CONDE, Derecho Penal, cit. nota No 32, p. 336; VIVES, Tomás; ORTS, Enrique; CARBONELL, Juan Carlos; GONZÁleZ, José Luis; MARTínEZ-BUJÁN, Carlos, Derecho Penal, Parte Especial, $3^{\circ}$ edición, Valencia: Tirant lo Blanch, 2010, p. 316.

${ }^{41}$ GÓMEZ, "Omisión del deber de socorro", cit. nota $\mathrm{N}^{\circ}$ 33, p. 297; VIVES; ORTS; CARBONELL; GONZÁlEZ; MARTÍNEZ-BUJÁN, Derecho Penal, cit. nota N 40, p. 316; BLANCO, Carlos, La omisión del deber de socorro en el Derecho Penal, Barcelona: J.M. Bosch, 2009, p. 208. No obstante la modificación legal efectuada, actualmente existe una parte de la doctrina española que de todas maneras rechaza la tesis causalista, argumentando que, si bien el texto del artículo $195 \mathrm{~N}^{\circ} 3$ comprende los accidentes causados fortuitamente, tal hipótesis calificada exige, en todo caso, que el accidente haya sido "ocasionado" por el imputado, elemento que concurrirá únicamente cuando el hecho sea imputable objetivamente a un riesgo permitido o prohibido creado por aquél. Ver DOPICO, Jacobo, “Omisión de socorro”, cit. nota N³4, pp. 269 y ss.
} 
ESCOBAR, Javier. "Sujeto activo del delito de omisión de auxilio en accidentes de tránsito".

Como primer argumento, los partidarios de esta postura han recurrido al significado de la expresión accidente, concepto que incorporaría aquellos eventos ocasionados fortuitamente $^{42}$. Desde esta perspectiva, accidente podría definirse como un suceso que involuntariamente causa daño a las personas o a las cosas. Con anterioridad a la reforma del artículo $195 \mathrm{~N}^{\circ} 3$, la doctrina española invocaba, en favor de la incorporación de los sucesos fortuitos, el antiguo artículo 6 bis del Código Penal, el cual señalaba que los hechos ocasionados sin dolo ni culpa (por mero "accidente") se reputarían fortuitos, no siendo punibles $^{43}$.

¿Posee el Código Penal chileno un concepto inequívoco de "accidente"? La respuesta es negativa, toda vez que esta expresión es utilizada en a lo menos dos sentidos diversos. Así, mientras que en algunas disposiciones tal concepto se asimila al de caso fortuito (por ejemplo, artículo $10 \mathrm{~N}^{\circ} 8$, el cual exime de responsabilidad al que "con ocasión de ejecutar un acto lícito, con la debida diligencia, causa un mal por mero accidente"), en otras se utiliza simplemente como sinónimo de "hecho", como acontece en los artículos 325, 326 y 329.

En efecto, el artículo 323 sanciona al que destruyere o descompusiere una vía férrea, o colocare obstáculos que pudieren producir el descarrilamiento. Luego, los artículos 325 y 326 se erigen como hipótesis calificadas de la conducta descrita anteriormente, graduando la pena a aplicar según el resultado provocado por el "accidente". Lo anterior significa que ambos artículos utilizan este concepto en un contexto donde la conducta ejecutada por el agente es, en términos subjetivos, plenamente imputable. Por su parte, el artículo 329 sanciona al que, por ignorancia culpable, imprudencia o descuido, causare un accidente que lesione o dañe a otro. En este segundo caso, como se puede apreciar, el Código utiliza el concepto "accidente" en un contexto en que exige un obrar culposo por parte del agente.

En conclusión, no es posible sostener que el Código Penal chileno posea un significado inequívoco de la expresión "accidente", existiendo a lo menos dos sentidos diversos en que tal concepto es utilizado: El primero de ellos como sinónimo de caso fortuito, y el segundo simplemente como sinónimo de hecho.

\subsection{Solidaridad como bien jurídico protegido o fundamento del delito de omisión de auxilio en accidentes de tránsito}

La existencia de un deber general de solidaridad, ya sea como bien jurídico protegido o como fundamento del delito en estudio, es un argumento que, si bien no siempre de manera explícita, se encuentra presente en el planteamiento causalista ${ }^{44}$. Un deber de tal naturaleza podría justificar la imposición de obligaciones de socorro y colaboración a todos los conductores involucrados en el específico accidente, prescindiendo de consideraciones valorativas.

\footnotetext{
${ }^{42}$ HUERTA, Susana, "Injerencia y art. 489 bis, $3^{\circ}$ CP.”, Anuario de Derecho Penal y Ciencias Penales, Año

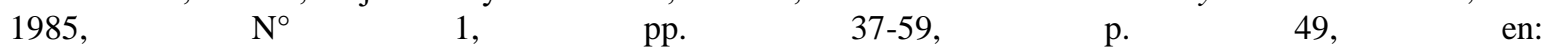
https://www.boe.es/publicaciones/anuarios_derecho/anuario.php?id=P_1985_ANUARIO_DE_DERECHO_P ENAL_Y_CIENCIAS_PENALES [visitado el 22/12/2017].

${ }^{43}$ HUERTA, "Injerencia", cit. nota $N^{\circ} 42$, p. 49.

${ }^{44}$ Sentencia Roj 2.091/1988, de fecha 23 de marzo de 1988, Tribunal Supremo de España.
} 
Polit. crim. Vol. 13, № 26 (Diciembre 2018) Art. 9, pp. 1003-1026.

[http://www.politicacriminal.cl/Vol_13/n_26/Vol13N26A9.pdf]

Actualmente la idea de solidaridad se encuentra presente en diversas áreas del ordenamiento jurídico, tales como el derecho de la seguridad social ${ }^{45}$, derecho privado ${ }^{46}$, derecho de familia $^{47}$, filosofía del derecho ${ }^{48}$ y derecho penal ${ }^{49}$, entre otros. Sin perjuicio de lo anterior, el concepto mismo de solidaridad, muchas veces caracterizado por su imprecisión y generalidad, es todavía materia de discusión ${ }^{50}$. Al respecto, es posible afirmar que la mayoría de las veces que se utiliza esta expresión se hace referencia a un vínculo existente entre distintas personas, por su sola condición de tal, como consecuencia del cual se brinda auxilio o se toleran ciertas acciones ${ }^{51}$. Desde esta perspectiva, la solidaridad constituiría una virtud $^{52}$ y el trasfondo de conductas desinteresadas en beneficio de otras personas.

Sin embargo, en el ámbito jurídico tal concepto debe ser restringido. El derecho no tiene la función de generar actitudes o sentimientos en las personas, ni menos exigirles una señal determinada de unión o de co-pertenencia con otras. Por tanto, la solidaridad como principio jurídico debe limitarse a requerir un actuar u omitir externo ${ }^{53}$. Así, mediante el establecimiento de "leyes del buen samaritano" el Estado exige a las personas que ayuden a otro $^{54}$. Lo anterior tiene como consecuencia que las acciones impuestas o requeridas de esta forma no son propiamente solidarias ${ }^{55}$, sino que representan una "cuasi-solidaridad" 56 .

${ }^{45}$ OBANDO, Iván, "El derecho a la seguridad social en el constitucionalismo chileno: Un continente en busca de su contenido", Revista de Estudios Constitucionales, Año 2012, N ${ }^{\circ}$ 1, pp. 289-338, p. 329, en: http://www.scielo.cl/scielo.php?script=sci_arttext\&pid=S0718-52002012000100008 [visitado el 01/01/2018].

${ }^{46}$ AGUILAR, Gonzalo, "Principio de solidaridad y derecho privado: Comentario a una sentencia del Tribunal Constitucional", Revista Ius et Praxis, Año $\mathrm{N}^{\circ}$ 14, $\mathrm{N}^{\circ}$ 2, pp. 593-610, en: http://www.scielo.cl/scielo.php?script=sci_arttext\&pid=S0718-00122008000200017 [visitado el 01/01/2018].

47 LEPIN, Cristián, "Los nuevos principios del derecho de familia", Revista Chilena de Derecho Privado, Año 2014, $\mathrm{N}^{\circ}$ 23, pp. 9-55, p. 22, en: http://www.scielo.cl/scielo.php?script=sci_arttext\&pid=S071880722014000200001 [visitado el 01/01/2018].

${ }^{48}$ VIDAL, Ernesto, "Sobre los derechos de solidaridad. Del Estado liberal al social y democrático de Derecho", Anuario de Filosofía del Derecho, Año 1993, $\mathrm{N}^{\circ}$ 10, pp. 89-110, en: https://www.boe.es/publicaciones/anuarios_derecho/anuario.php?id=F_1993_ANUARIO_DE_FILOSOF\%C DA_DEL_DERECHO [visitado el 01/01/2018].

${ }^{49}$ FRISCH, Wolfgang, "Derecho penal y solidaridad", Indret: Revista para el Análisis del Derecho, Año 2016, N 4, A. 15, pp. 1-24, p. 3, en: http://www.indret.com/pdf/1255.pdf [visitado el 02/03/2017].

${ }^{50}$ FRISCH, "Derecho penal y solidaridad", cit. nota $N^{\circ} 49$, p. 6; VAN WEEZEL, "Solidaridad", cit. nota $N^{\circ}$ 19 , p. 194.

${ }^{51}$ FRISCH, "Derecho penal y solidaridad", cit. nota $\mathrm{N}^{\circ} 49$, p. 7.

${ }^{52}$ VIDAL, "Sobre los derechos de solidaridad", cit. nota $\mathrm{N}^{\circ} 48$, p. 93.

${ }^{53}$ FRISCH, "Derecho penal y solidaridad", cit. nota $\mathrm{N}^{\circ} 49$, pp. 7 y 17.

54 RAGUÉS, Ramón, "Proceso al buen samaritano. Acciones de salvamento y responsabilidad por daños", Indret: Revista para el Análisis del Derecho, Año 2001, $\mathrm{N}^{\circ}$ 2, A. 2, pp. 1-12, p. 2, en: http://www.indret.com/pdf/049_es.pdf [visitado el 01/01/2018]; VALENZUELA, Jonatan, "La narrativa del deber de ayudar a otro: Samaritanos, héroes y superhéroes”, Revista Ius et Praxis, Año $\mathrm{N}^{\circ} 20, \mathrm{~N}^{\circ} 2$, pp. 555574, pp. 556 y 557, en: http://www.scielo.cl/pdf/iusetp/v20n2/art17.pdf [visitado el 01/01/2018].

${ }^{55}$ FARALDO, “Omisión del deber de socorro", cit. nota $\mathrm{N}^{\circ} 32$, p. 531.

${ }^{56}$ VAN WEEZEL, "Solidaridad", cit. nota N 19, p. 195; FRISCH, "Derecho penal y solidaridad", cit. nota N 49, p. 7; VIVES; ORTS; CARBONELL; GONZÁLEZ; MARTÍNEZ-BUJÁN, Derecho Penal, cit. nota Nº 40, p. 311. 
ESCOBAR, Javier. "Sujeto activo del delito de omisión de auxilio en accidentes de tránsito".

En materia de deberes, actualmente se distingue entre negativos y positivos ${ }^{57}$. Los primeros se refieren a la evitación de la ampliación del propio ámbito de organización a costa de los demás 58 . El "obligado negativo" tiene el deber de no atribuirse la organización que le compete a otro o de revertir tal atribución en caso de que ella ya haya tenido lugar ${ }^{59}$. Por su parte, los deberes positivos son propios de quien ocupa un "estatus especial". El "obligado positivo" no sólo tiene que garantizar que de su organización no se derivarán efectos lesivos (lo que constituye un deber negativo), sino que debe preocuparse de la existencia del círculo de organización de la persona favorecida o incluso de su fomento ${ }^{60}$.

Los deberes positivos pueden ser generales o especiales. Mientras los primeros se dirigen a todos los ciudadanos y tienen como fundamento general la solidaridad intersubjetiva ${ }^{61}$, los segundos, en cambio, se dirigen únicamente al portador de un "estatus especial", condición que se adquiere tras el ingreso voluntario en una institución ${ }^{62}$ (por ejemplo, la Administración Pública) ${ }^{63}$.

¿Es la solidaridad el bien jurídico protegido o el fundamento del delito de omisión de auxilio en accidentes de tránsito?

En cuanto a la primera opción, la doctrina mayoritaria es contraria a ella ${ }^{64}$. Se argumenta que un derecho penal liberal no puede proteger sin más la solidaridad interpersonal, concepto que, a pesar de los esfuerzos, continúa siendo vago e impreciso, características que le impedirían limitar el ámbito de aplicación del tipo penal ${ }^{65}$. Por lo demás, la solidaridad no puede ser considerada un fin en sí misma, En efecto, cuando las personas actúan de manera solidaria lo hacen motivadas por algo, interés que representa el fin perseguido. Por ejemplo, cuando alguien ayuda a una persona herida lo hace para mejorar las condiciones de existencia de ésta, y no para proteger la "solidaridad"66.

57 JAKOBS, Günther, Derecho penal. Parte general. Fundamentos y teoría de la imputación, $2^{\circ}$ edición, Trad. CUELLO, Joaquín; SERRANO, José Luis, Madrid: Marcial Pons, 1997, pp. 1022 y ss.

${ }^{58}$ ROBLES, Ricardo, "Deberes negativos y positivos en Derecho penal", Indret: Revista para el Análisis del Derecho, Año 2013, $\quad N^{\circ} \quad 4, \quad$ A. $\quad 12, \quad$ pp. $\quad 1-21, \quad$ p. $\quad 3$, en http://www.indret.com/code/getPdf.php?id=1699\&pdf=1008.pdf [visitado el 24/08/2017].

59 NAVAS, Iván, "Acción y omisión en infracción de deberes negativos en Derecho penal", Política

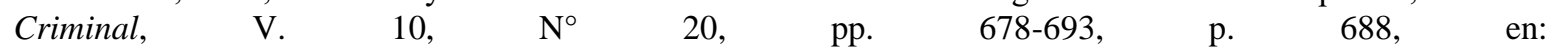
http://www.politicacriminal.cl/Vol_10/n_20/Vol10N20A8.pdf [visitado el 29/03/2017].

${ }^{60}$ ROBLES, "Deberes negativos", cit. nota $\mathrm{N}^{\circ} 58$, p. 3.

${ }^{61}$ NAVAS, “Acción y omisión”, cit. nota N 59, p. 680; ROBLES, “Deberes negativos”, cit. nota N 58, p. 6.

${ }^{62}$ Sobre el concepto de "institución”, ver ROBLES, "Deberes negativos”, cit. nota N 58, pp. 7 a 13.

${ }^{63}$ ROBLES, "Deberes negativos", cit. nota $N^{\circ} 58$, p. 7.

${ }^{64}$ A favor de la solidaridad como bien jurídico protegido en el delito de omisión de socorro, MUÑOZ CONDE, Derecho Penal, cit. nota $N^{\circ} 32$, pp. 330 y 331.

${ }^{65}$ BUSTOS, Miguel, "Bien jurídico y sanción penal en el delito de omisión del deber de socorro", Foro. Revista de ciencias jurídicas y sociales, $\quad \mathrm{V} .15, \quad \mathrm{~N}^{\circ} 2, \quad$ pp. 157-183, p. 171, en: https://revistas.ucm.es/index.php/FORO/issue/view/2354/showToc [visitado el 20/12/2017].

${ }^{66}$ BASILE, “Articolo 189”, cit. nota N 14, pp. 1, 2 y 2554; BUSTOS, Miguel, "La pluralidad de sujetos en el delito de omisión del deber de socorro: algunas cuestiones dogmáticas", Revista Jurídica Universidad Autónoma de Madrid, Año 2012, $\mathrm{N}^{\circ}$ 25, pp. 49-69, pp. 53 y 65, en: https://revistas.uam.es/revistajuridica/article/view/5964 [visitado el 20/12/2017]; FARALDO, "Omisión del deber de socorro", cit. nota $\mathrm{N}^{\circ}$ 32, p. 531; VIVES; ORTS; CARBONELL; GONZÁLEZ; MARTÍNEZBUJÁN, Derecho Penal, cit. nota $\mathrm{N}^{\circ} 40$, p. 311 
Polit. crim. Vol. 13, № 26 (Diciembre 2018) Art. 9, pp. 1003-1026.

[http://www.politicacriminal.cl/Vol_13/n_26/Vol13N26A9.pdf]

En relación a la segunda opción (solidaridad como fundamento de la norma de incriminación), ésta igualmente debe ser rechazada. Primero, cabe recordar que el ordenamiento penal reconoce la solidaridad como fundamento de deberes generales sólo en casos excepcionales. Dos ejemplos paradigmáticos de lo anterior son el delito de omisión de socorro del artículo $494 \mathrm{~N}^{\circ} 14$ del Código Penal ${ }^{67}$ y el estado de necesidad justificante ${ }^{68}$.

Ahora, respecto al específico caso del delito de omisión de auxilio en accidentes de tránsito, la propia estructura del tipo penal descarta que estemos en presencia de un deber general de solidaridad. Mientras la característica principal de estos deberes (fundados en aquel vínculo existente entre diversas personas por su sola condición de vivir en comunidad) es su extensión irrestricta, pues alcanzan a $\operatorname{todos}^{69}$, el artículo 195 únicamente dirige sus mandatos al "conductor que hubiere participado en el accidente", liberando de tales obligaciones a todos quienes no reúnan dicha calidad.

La situación descrita contrasta de manera evidente con el sistema italiano. En efecto, el artículo 189 del Codice della Strada impone sus mandatos a todo "utente della strada" involucrado en el accidente, expresión que incorpora a sujetos distintos de los conductores, tales como pasajeros y peatones. La amplitud de la regulación italiana se ve reforzada por el extenso significado que la doctrina atribuye a la expresión "accidente", el cual puede ser de cualquier clase y verificarse incluso sin colisión de dos o más cuerpos ${ }^{70}$.

Además de lo anterior, se debe considerar que es perfectamente posible que en un mismo accidente haya personas responsables por el delito del artículo $195 \mathrm{y}$, al mismo tiempo, sujetos imputados por el delito de omisión de socorro del artículo $494 \mathrm{~N}^{\circ} 14$ (por ejemplo, peatones) $)^{71}$.

Imaginemos el siguiente caso: "A" conduce su vehículo por un camino interurbano. Al llegar a un punto determinado, de manera imprevista un peatón ("B") atraviesa el camino por un paso no habilitado. "A" alcanza a reaccionar y, para evitar atropellar a "B", desvía ligeramente su trayectoria, impactando el vehículo conducido por "C". Como consecuencia del accidente, ambos conductores sufren lesiones menos graves. "B", quien presencia la colisión, abandona el lugar sin verificar el estado de los lesionados. "C", por su parte, al ver que "A" desciende de su automóvil sin mayores complicaciones, decide dirigirse a la ciudad más cercana y concurrir a un recinto asistencial para tratar sus heridas.

\footnotetext{
${ }^{67}$ ETCHEBERRY, Alfredo, Derecho Penal, T. IV, $3^{\circ}$ edición, Santiago: Editorial Jurídica de Chile, 1997, p. 19; NAVAS, “Acción y omisión”, cit. nota $\mathrm{N}^{\circ} 59$, p. 680.

${ }^{68}$ FRISCH, "Derecho penal y solidaridad", cit. nota $\mathrm{N}^{\circ} 49$, p. 4; WILENMANN, Javier, "El fundamento del estado de necesidad justificante en el derecho penal chileno. Al mismo tiempo, introducción al problema", Revista de Derecho Universidad Austral, V. XXVII, N ${ }^{\circ}$ 1, pp. 213-244, pp. 234 y ss., en: http://www.scielo.cl/pdf/revider/v27n1/art10.pdf [visitado el 19/06/2017]; COCA, Ivó, "Entre la responsabilidad y la solidaridad. El estado de necesidad defensivo", Indret: Revista para el Análisis del Derecho, Año 2011, N 1, A. 18, pp. 1-40, en: http://www.indret.com/pdf/789.pdf [visitado el 19/06/2017].

${ }^{69}$ FRISCH, "Derecho penal y solidaridad", cit. nota $\mathrm{N}^{\circ} 49$, p. 4.

${ }^{70}$ BASILE, “Articolo 189", cit. nota $\mathrm{N}^{\circ}$ 14, p. 2555.

${ }^{71}$ En este mismo sentido se pronuncian CARINGELLA; DE PALMA; FARINI; TRINCI, Manuale, cit. nota $\mathrm{N}^{\circ} 25$, p. 968.
} 
ESCOBAR, Javier. "Sujeto activo del delito de omisión de auxilio en accidentes de tránsito".

Conforme al planteamiento causalista, "C" sería autor del delito contemplado en el artículo 195 inciso segundo, toda vez que contribuyó con una condición causal a la producción del accidente. A pesar de que la conducta de "B" posee indudablemente un mayor grado de reproche, él no podría ser autor del delito indicado, pues no reúne la calidad especial de "conductor". A su respecto únicamente podría configurarse el ilícito de omisión de socorro.

Siendo la solidaridad el fundamento del delito de omisión de socorro, si se aceptase igual sustrato material para el ilícito de omisión de auxilio en accidentes de tránsito, ¿cómo podría explicarse la sideral diferencia penológica entre ambas figuras? Mientras que "B", principal "responsable" del acontecimiento, sería sancionado con una pena de multa de una a cuatro unidades tributarias mensuales, el conductor " $C$ ", quien dio cumplimiento a todas las normas de cuidado establecidas, sería condenado a presidio menor en su grado medio, inhabilidad perpetua para conducir vehículos de tracción mecánica y multa de siete a diez unidades tributarias mensuales. Pareciera claro que la idea de solidaridad no se encuentra en condiciones de explicar la estructura del tipo penal en estudio, y tampoco de justificar adecuadamente el diverso tratamiento penológico descrito.

Como último punto, resulta pertinente citar la interpretación desarrollada por van Weezel a propósito de la anterior regulación del artículo $195^{72}$. En opinión del autor, el antiguo delito de omisión de auxilio comprendía, desde el punto de vista de sus fundamentos, dos grupos de situaciones: 1. Casos de conducción temeraria o antirreglamentaria con resultados no imputables, o que no excedían las lesiones simplemente graves; y 2. Casos de conducción dentro del riesgo permitido en que el conductor igualmente estaba obligado, bajo amenaza de pena, a detener la marcha y prestar ayuda. Mientras que en el primer grupo de casos se trataba de un tipo penal de peligro abstracto, en el segundo el legislador había establecido un delito cuyo fundamento era la pura infracción de un deber de solidaridad ${ }^{73}$.

En relación a la pena prevista, cabe destacar que el tribunal podía decidir aplicar o no la sanción corporal. Conforme a lo anterior, según la interpretación de van Weezel las penas privativas de libertad de cierta consideración debían estar reservadas para los casos en que al conductor sancionado le cabía alguna responsabilidad en el accidente. En cambio, allí donde sólo se podía constatar el quebrantamiento de un deber de solidaridad, la sanción debía mantenerse por debajo de la privación de libertad o, en casos excepcionales, en el mínimo de ésta. Lo anterior, en palabras del autor, no significaba socavar la idea de solidaridad, sino situarla en la dimensión que le correspondía ${ }^{74}$.

¿Sería posible mantener la interpretación descrita precedentemente? Considerando que las premisas centrales de ésta estaban basadas en la antigua redacción del artículo 195, resulta

\footnotetext{
72 “Artículo 195.- El incumplimiento, a sabiendas, de lo señalado en el artículo 168 será sancionado con multa de tres a siete unidades tributarias mensuales y con la suspensión de su licencia hasta por un mes. El incumplimiento, a sabiendas, de lo señalado en el artículo 176 será sancionado con la suspensión de la licencia de conductor por un plazo máximo de doce meses y si el juez así lo estimare, presidio menor en grado mínimo a medio, salvo que las lesiones producidas tengan el carácter de leves, en cuyo caso se aplicará la sanción del inciso primero del artículo 193".

${ }^{73}$ VAN WEEZEL, "Solidaridad", cit. nota N 19, p. 194.

${ }^{74}$ VAN WEEZEL, "Solidaridad", cit. nota N 19, p. 203.
} 
Polit. crim. Vol. 13, № 26 (Diciembre 2018) Art. 9, pp. 1003-1026.

[http://www.politicacriminal.cl/Vol_13/n_26/Vol13N26A9.pdf]

claro que ella es incompatible con el texto actualmente vigente. En efecto, la imposición de la pena privativa de libertad es ahora imperativa, siendo incluso superior a la contemplada para el homicidio imprudente. Por tanto, sostener hoy que el fundamento del delito de omisión de auxilio continúa siendo un deber general de solidaridad situaría a ésta en una dimensión que no le corresponde.

\section{Hacia una concepción valorativa del sujeto activo en el delito de omisión de auxilio}

Habiendo revisado críticamente los dos principales fundamentos de la tesis causalista, y desarrollado las razones en virtud de las cuales los mismos debiesen ser rechazados, en el presente capítulo se propondrá una interpretación alternativa a la hasta ahora vigente.

Según mi opinión, el delito del artículo 195 exige, para efectos de configurar un sujeto activo idóneo, que los resultados lesivos ocasionados por el accidente, cuya conjuración se omite, sean imputables objetivamente a un riesgo prohibido ${ }^{75}$ creado previamente por el agente $^{76}$.

Conforme a la tesis acá propuesta, la mera intervención causal en el accidente constituye un requisito necesario, mas en ningún caso suficiente. Lo anterior no es sino expresión de un consenso generalizado, según el cual la construcción de responsabilidad y la imputación jurídico penal debe basarse en criterios normativos y no "naturalísticos" como lo es el de la causalidad $^{77}$.

\subsection{Significado de la expresión "participar"}

Conforme al texto expreso del artículo 195, las obligaciones allí contenidas únicamente son impuestas al conductor que hubiere "participado" en el accidente de tránsito. Tal restricción legal del círculo de "obligados especiales" representa una nota característica del sistema chileno $^{78}$. Fundamental resulta entonces analizar el significado de esta expresión.

¿Respecto de quién puede decirse que ha "participado" en un hecho?

El legislador chileno utiliza, en materia penal, la expresión "participar" en diversas disposiciones, todas las cuales, cuando hacen referencia a una persona, excluyen la mera

\footnotetext{
75 Entendemos por "riesgo" la posibilidad del acaecimiento de determinados cursos con consecuencias no deseadas, especialmente aquellas captadas por los tipos penales de los distintos delitos. FRISCH, Wolfgang, Estudios sobre Imputación Objetiva, Santiago, Thomson Reuters, 2012, p. 40.

${ }^{76}$ Sobre la teoría de la imputación objetiva, ver ROXIN, Claus, Derecho Penal, T. I, cit. nota N ${ }^{\circ} 12$, pp. 362 y ss.; FRISCH, Estudios sobre Imputación Objetiva, cit. nota $\mathrm{N}^{\circ} 75$, pp. 16 y ss. Por tanto, cuando las lesiones o daños provocados únicamente sean imputables a riesgos permitidos no será posible apreciar un sujeto activo idóneo. Sobre la noción de riesgo permitido, ver FRISCH, Estudios sobre Imputación Objetiva, cit. nota $\mathrm{N}^{\circ}$ 75, pp. 41 y 42; ROXIN, Claus, Derecho Penal, T. I, cit. nota $\mathrm{N}^{\circ} 12$ p. 371

${ }^{77}$ HERNÁNDEZ, Héctor, "El problema de la "causalidad general" en el derecho penal chileno (con ocasión del art. 232 del Anteproyecto de Nuevo Código Penal)", Política Criminal, V. 1, N 1, A.7, pp. 1-33, pp. 8 y 9, en http://www.politicacriminal.cl/n_01/pdf_01/a_7.pdf [visitado el 22/04/2017]; DOPICO, “Omisión de socorro", cit. nota $\mathrm{N}^{\circ} 34$, pp. 240 y 241.

${ }^{78}$ En efecto, tal restricción contrasta, ya sea por su existencia o su intensidad, con la regulación existente en España, Italia y Alemania (\$142 del Código Penal).
} 
ESCOBAR, Javier. "Sujeto activo del delito de omisión de auxilio en accidentes de tránsito".

intervención causal como elemento suficiente para configurar una "participación". En este sentido destacan los artículos $10 \mathrm{~N}^{\circ} 5$ (legítima defensa de terceros), $12 \mathrm{~N}^{\circ} 21,17,150$ inciso segundo, 168, 176, 183 inciso primero, 269 ter, 366 quinquies (delito de producción de material pornográfico infanto-juvenil) ${ }^{79}$ y 489 inciso segundo, todos del Código Penal.

Consideremos el siguiente caso: "A" le pide a "B" un megáfono, señalándole que lo necesita para un evento, solicitud a la cual éste accede. Cuando "A" se dirige a su escuela, se encuentra con " $C$ ", un antiguo enemigo. En dicho momento, " $A$ ", utilizando el megáfono, insulta a "C", quien se ofusca y lo golpea. La agresión es vista por "B", quien intercede en defensa de " $A$ ".

Suponiendo que los insultos proferidos por "A" constituyen una provocación suficiente en los términos del artículo $10 \mathrm{~N}^{\circ} 5$ del Código Penal, ¿ha participado " $\mathrm{B}$ " en tal provocación ${ }^{80}$ ? Pareciera claro que, a pesar de su intervención causal en los acontecimientos, representaría un abuso afirmar que "B" ha participado en la provocación desplegada por "A".

El propio sentido común del lenguaje respalda las conclusiones anteriormente expuestas. Según el Diccionario de la Real Academia de la Lengua Española, "participar” significa "tomar parte en algo", acepción que, por cierto, implica algo más una contribución causal. Por ejemplo, si un estudiante universitario le presta a otro su computador para que éste pueda escribir un ensayo, ¿ha "participado" el primer estudiante en la elaboración de tal trabajo? Imaginemos que, una vez entregado el ensayo, el profesor del curso pregunta quién ha "tomado parte" en aquél. ¿Alguien podría responder afirmativamente respecto del primer estudiante? Claramente la respuesta es negativa.

La expresión utilizada por el artículo 195 contrasta, en este punto, con los términos empleados en el artículo 189 del Codice della Strada italiano, norma que posee, a diferencia del primero, una estructura marcadamente causalista. La regulación chilena difiere, asimismo, de aquella establecida en el $\$ 142$ del Código Penal alemán, norma que sanciona al partícipe de un accidente de tránsito que se aleje del lugar de los hechos sin antes haber cumplido los mandatos allí establecidos ${ }^{81}$. En efecto, el inciso quinto del $\$ 142$ dispone que, para efectos de tal delito, "partícipe en un accidente" será toda persona cuyo comportamiento, según las circunstancias, pueda haber contribuido a la causación del accidente. Como se puede apreciar, el legislador alemán, consciente del significado de la expresión "participar", decidió ampliarlo a propósito de este específico delito. La ausencia

\footnotetext{
${ }^{79}$ Sobre los problemas específicos que presenta la intervención delictiva en este delito, ver RODRÍGUEZ, Luis, "Autoría y participación en el delito de producción de material pornográfico infanto-juvenil", Revista de Derecho de la Pontifica Universidad Católica de Valparaíso, V. 45, $\mathrm{N}^{\circ}$ 2, pp. 131-150, en: http://www.rdpucv.cl/index.php/rderecho/article/view/1065/900 [visitado el 21/08/2017].

80 “Artículo 10. Están exentos de responsabilidad criminal: (...)

$5^{\circ}$ El que obra en defensa de la persona o derechos de su cónyuge, de su conviviente civil, de sus parientes (...), siempre que concurran la primera y segunda circunstancias prescritas en el número anterior, y la de que, en caso de haber precedido provocación de parte del acometido, no tuviere participación en ella el defensor".

${ }^{81}$ Al respecto, ver KUHLEN, Lothar, "Características, problemas dogmáticos e importancia práctica del derecho penal alemán de circulación vial”, Indret: Revista para el Análisis del Derecho, Año 2013, N ${ }^{\circ} 2$, A. 13, pp. 1-29, pp. 16 a 20, en: http://www.indret.com/pdf/968_kuhlen.pdf [visitado el 06/01/2018].
} 
Polit. crim. Vol. 13, № 26 (Diciembre 2018) Art. 9, pp. 1003-1026.

[http://www.politicacriminal.cl/Vol_13/n_26/Vol13N26A9.pdf]

de una intervención legislativa similar en el sistema chileno obliga, por tanto, a interpretar la expresión "participar" conforme a su sentido original, descartando la mera intervención causal como elemento suficiente para su configuración ${ }^{82}$.

\subsection{Contenido y alcance del artículo $201 \mathrm{~N}^{\circ} 15$, y su relación con los artículos 195,176 y 168}

Como segundo argumento en favor de la tesis propuesta, cabe tener presente la interpretación sistemática de los artículos $201 \mathrm{~N}^{\circ} 15,195,176$ y 168.

El artículo $201 \mathrm{~N}^{\circ} 15$ dispone:

"Artículo 201.- Son infracciones o contravenciones menos graves, las siguientes:

$(\ldots)$

15. No cumplir las obligaciones que impone el artículo 176".

Como es posible apreciar, el artículo transcrito califica como infracción menos grave, asunto de competencia del Juzgado de Policía Local, el incumplimiento de las mismas obligaciones cuya inobservancia sanciona el artículo 195 a título de delito. Existiendo dos normas que regulan idéntica materia, se vuelve necesario encontrar alguna diferencia entre ambas disposiciones, a fin de distinguir sus campos de aplicación.

Conforme al planteamiento causalista, tal diferenciación se vuelve imposible. En efecto, siempre que un conductor involucrado en un accidente de tránsito omitiese los deberes establecidos en el artículo 176 configuraría, sin más, el delito de omisión de auxilio. Como consecuencia, la postura causalista priva de aplicación al artículo $201 \mathrm{~N}^{\circ} 15$, situación que no resulta admisible.

Por tanto, el delito del artículo 195 debe necesariamente exigir algún elemento que el 201 $\mathrm{N}^{\circ} 15$ no. Desde este punto de vista, la primera constituye una norma especial en relación a la segunda, toda vez que, además de contemplar todos sus requisitos, exige un "elemento de especialidad $^{83}$. Éste, como se ha señalado, consiste en la exigencia de que los resultados lesivos ocasionados por el accidente sean objetivamente imputables a un riesgo prohibido creado por el conductor.

Además de lo anterior, cabe considerar que la contravención menos grave sanciona únicamente el incumplimiento de los deberes establecidos en el artículo 176, vale decir,

\footnotetext{
${ }^{82}$ La Corte Suprema chilena, en su sentencia Rol 35.715-2017, sostuvo que la expresión "participar" exige únicamente que el conductor haya intervenido causalmente en el accidente. Lamentablemente, la sentencia no desarrolla suficientemente las razones en virtud de las cuales arriba a tal conclusión, ni considera las múltiples normas en que la expresión "participar" posee un significado distinto, conforme se ha explicado en los párrafos precedentes.

${ }^{83}$ MARINUCCI; DOLCINI, Manuale, cit. nota No 13, p. 519.
} 
ESCOBAR, Javier. "Sujeto activo del delito de omisión de auxilio en accidentes de tránsito".

aquellos mandatos que surgen cuando el accidente ha provocado lesiones o muertes, mas no aquellos a que se refiere el artículo 168.

El sistema diseñado por la Ley de Tránsito puede entonces resumirse de la siguiente manera:

a. Accidentes donde únicamente se hubieren provocado daños, mas éstos no sean imputables objetivamente a la conducta previa del conductor omitente: En estas situaciones, la omisión de los mandatos indicados en el artículo 168 no podrá ser sancionada conforme al artículo 195 (al no cumplirse el requisito especial relativo al sujeto activo) ni por el artículo $201 \mathrm{~N}^{\circ}$ 15, pues éste únicamente sanciona la omisión de los mandatos contemplados en el artículo 176.

b. Accidentes que hubieren provocado lesiones o muertes no imputables objetivamente a la conducta previa del conductor omitente: En estos casos tampoco será posible sancionar al agente por el delito del artículo 195 (al no cumplirse el requisito especial relativo al sujeto activo). Sin embargo, el conductor podrá ser sancionado conforme a la contravención menos grave contemplada en el artículo $201 \mathrm{~N}^{\circ} 15$, sin perjuicio además de su eventual responsabilidad por la comisión otros ilícitos (por ejemplo, el delito de omisión de socorro del artículo $494 \mathrm{~N}^{\circ} 14$ del Código Penal).

c. Accidentes que hubieren provocado daños, lesiones o muertes imputables objetivamente a la conducta previa del conductor omitente: Finalmente, en estas hipótesis estaremos ante un sujeto activo idóneo para efectos de configurar el delito de omisión de auxilio del artículo 195.

El sistema expuesto precedentemente se fundamenta en las siguientes premisas:

La obligación general de asistencia, que grava indiferenciadamente a todos los ciudadanos, está representada por el delito de omisión de socorro.

El carácter fortuito de un accidente no permite, bajo amenaza de sanción penal, aumentar los deberes generales de auxilio y colaboración del agente, precisamente por ser ajeno a su voluntad $^{84}$. ¿Cómo se podría justificar un aumento de pena respecto a un conductor que, pese a haber respetado todas las normas de cuidado establecidas, se ha visto involucrado en un accidente de tránsito por mero acaso? Si se aceptase la sola intervención causal como fundamento suficiente para aumentar los deberes generales de asistencia, tal consideración sería válida para todos los ámbitos de la vida en sociedad, no solamente para los conductores de vehículos motorizados.

Lo anterior permite explicar la existencia del artículo $201 \mathrm{~N}^{\circ} 15$. Al no ser suficiente, para efectos de aumentar la sanción penal, el carácter fortuito del accidente, el legislador ha establecido una sanción administrativa especial para el incumplimiento de los deberes de auxilio y colaboración en este específico contexto.

\footnotetext{
${ }^{84}$ En el mismo sentido, BLANCO, La omisión del deber de socorro, cit. nota $\mathrm{N}^{\circ}$ 41, p. 218.
} 


\section{Polit. crim. Vol. 13, № 26 (Diciembre 2018) Art. 9, pp. 1003-1026. \\ [http://www.politicacriminal.cl/Vol_13/n_26/Vol13N26A9.pdf]}

Ahora, cuando los resultados lesivos ocasionados por el accidente sean objetivamente imputables a un riesgo prohibido creado por el conductor, éste se sitúa en una situación especial $^{85}$, la cual genera obligaciones adicionales cuyo incumplimiento sanciona el artículo 195. Además, conforme al inciso cuarto de la misma norma, la sanción por este ilícito se impondrá conjuntamente con aquella que le corresponda al conductor por el respectivo delito o cuasidelito cometido previamente. De esta forma, el legislador ha distinguido en forma clara los dos núcleos fácticos involucrados: 1. Conducta previa creadora de un riesgo prohibido; y 2. Incumplimiento de los mandatos establecidos.

\subsection{Entidad de las penas establecidas en el artículo 195}

Como tercer y último argumento en favor de la tesis propuesta, corresponde analizar la entidad de las penas establecidas en el artículo 195.

$\mathrm{Al}$ respecto, destaca inmediatamente la severidad de las sanciones privativas de libertad y de inhabilidad para conducir vehículos de tracción mecánica.

En efecto, el inciso segundo del artículo 195 establece, para aquellos casos en que el accidente ha provocado lesiones leves, menos graves o simplemente graves, penas de presidio menor en su grado medio e inhabilidad perpetua para conducir vehículos de tracción mecánica. Si se comprara estas sanciones con aquellas contempladas para el delito de manejo en estado de ebriedad con resultado de lesiones simplemente graves (artículo 196 inciso segundo), llama la atención que la pena privativa de libertad sea la misma y que la sanción de inhabilidad para conducir vehículos sea mayor en el caso del artículo 195.

Por su parte, el inciso tercero del artículo 195 establece, para aquellas situaciones en que el accidente ha causado lesiones gravísimas o muertes, penas de presidio menor en su grado máximo, inhabilidad perpetua para conducir vehículos de tracción mecánica y el comiso del vehículo. Al comparar estas sanciones con aquellas previstas para el delito de manejo en estado de ebriedad con resultado de lesiones gravísimas o muerte (artículo 196 inciso tercero), la similitud entre ambos esquemas es evidente. Para el primer caso (lesiones gravísimas) la pena privativa de libertad es de presidio menor en su grado máximo, y para el segundo (muerte) de presidio menor en su grado máximo a presidio mayor en su grado mínimo. Además, en ambos se contempla la sanción de inhabilidad perpetua para conducir vehículos de tracción mecánica y el comiso del vehículo.

¿Podría la tesis causalista explicar razonablemente la entidad de las sanciones establecidas en el artículo 195, especialmente si se las compara con aquellas contempladas para el delito de manejo en estado de ebriedad?

A menos que se esté dispuesto a admitir una infracción al principio de proporcionalidad, la tesis causalista no se encuentra en condiciones de justificar correctamente la magnitud de las sanciones indicadas. En efecto, de acogerse el planteamiento causalista se producirían relevantes contradicciones penológicas, como por ejemplo:

\footnotetext{
${ }^{85}$ BLANCO, La omisión del deber de socorro, cit. nota $\mathrm{N}^{\circ}$ 41, p. 218.
} 
ESCOBAR, Javier. "Sujeto activo del delito de omisión de auxilio en accidentes de tránsito".

a. El conductor que, respetando todos y cada uno de los mandatos de cuidado establecidos, se viera involucrado en un accidente imputable exclusivamente a negligencia de otro, causando lesiones leves, debería ser sancionado, en caso de incumplimiento de los mandatos establecidos en el artículo 195, con presidio menor en su grado medio e inhabilitación perpetua para conducir vehículos de tracción mecánica. Tal situación representa un exceso, por cuanto si este imputado, manejando en estado de ebriedad, atropellase a un peatón causándole lesiones de igual entidad, sería sancionado con presidio menor en su grado mínimo y suspensión de su licencia de conducir por dos años.

b. Ahora, si las lesiones ocasionadas por el accidente fuesen gravísimas, el conductor (diligente) sería sancionado, en caso de incumplimiento de los mandatos establecidos en el artículo 195, con la misma pena que le correspondería si, manejando en estado de ebriedad, atropellase a una persona ocasionándole idénticas lesiones.

Las consideraciones precedentes abogan por el rechazo del planteamiento causalista y, al mismo tiempo, respaldan la tesis propuesta, conforme a la cual el delito del artículo 195, para efectos de apreciar un sujeto activo idóneo, requiere un elemento adicional a la mera intervención causal, a saber, que los resultados lesivos ocasionados por el accidente sean objetivamente imputables a un riesgo prohibido creado por el agente. Esta exigencia permite justificar adecuadamente las sanciones establecidas en el artículo 195, así como también el tratamiento penal diferenciado que se produce entre el conductor y las demás personas que no reúnan tal calidad -por ejemplo, peatones o pasajeros-, respecto de quienes únicamente regirá la obligación general de asistencia (omisión de socorro).

\section{Conclusiones}

a. El delito de omisión de auxilio en accidentes de tránsito, contemplado en el artículo 195, presenta diversos problemas dogmáticos. Uno de ellos consiste en determinar cuáles son los requisitos que debe reunir la persona sobre la cual recaerán los deberes de auxilio y colaboración ("obligado especial"). Al respecto, tanto en Chile como en el derecho comparado la opinión mayoritaria adscribe a un planteamiento causalista, conforme al cual los mandatos establecidos gravan, sin distinción, a todo conductor que haya contribuido con alguna condición causal a la producción del accidente.

b. Sin embargo, conforme se ha argumentado en el presente trabajo, tal tesis debe ser rechazada en el contexto del derecho penal chileno. En efecto, la estructura del delito del artículo 195 descarta la existencia de un deber general de solidaridad, ya sea como bien jurídico protegido o como fundamento de la norma de incriminación. Además, tampoco es posible sostener que el derecho penal chileno posea un significado inequívoco de la expresión "accidente", pues, tal como se ha demostrado, el Código Penal utiliza tal concepto en a lo menos dos sentidos diversos.

c. Conforme a la tesis alternativa acá propuesta, la mera contribución causal no es suficiente para efectos de apreciar un sujeto activo idóneo en el delito de omisión de auxilio en accidentes de tránsito, sino que, además, se requiere que los resultados lesivos 
Polít. crim. Vol. 13, № 26 (Diciembre 2018) Art. 9, pp. 1003-1026.

[http://www.politicacriminal.cl/Vol_13/n_26/Vol13N26A9.pdf]

ocasionados por el accidente, cuya conjuración se omite, sean imputables objetivamente a un riesgo prohibido creado previamente por el agente.

d. La tesis planteada se fundamenta principalmente en tres argumentos: 1 . La existencia de la contravención menos grave del artículo $201 \mathrm{~N}^{\circ} 15$, norma que sanciona el incumplimiento de los mismos mandatos que los incisos segundo y tercero del artículo 195; 2. La interpretación sistemática de la expresión "participar"; y 3. La estructura del tipo penal de omisión de auxilio y la entidad de las sanciones contempladas por éste. 
ESCOBAR, Javier. "Sujeto activo del delito de omisión de auxilio en accidentes de tránsito".

\section{Bibliografía}

AGUILAR, Gonzalo, "Principio de solidaridad y derecho privado: Comentario a una sentencia del Tribunal Constitucional", Revista Ius et Praxis, Año $\mathrm{N}^{\circ} 14, \mathrm{~N}^{\circ} 2$, pp. 593-610, en: http://www.scielo.cl/scielo.php?script=sci_arttext\&pid=S071800122008000200017 [visitado el 01/01/2018].

BALZANI, Simone; TRINCI, Alessandro, I reati in materia di circolazione stradale, Milano: Wolters Kluwer, 2016.

BASILE, Enrico, "Articolo 189. Comportamento in caso di incidente", en: DOLCINI, Emilio y GATTA, Gian Luigi (directores), Codice Penale Commentato, T. III, $4^{\circ}$ edizione, Milano: Wolters Kluwer, 2015, pp. 2551-2564.

BLANCO, Carlos, La omisión del deber de socorro en el Derecho Penal, Barcelona: J.M. Bosch, 2009.

BUSTOS, Juan, Manual de Derecho penal, Parte especial, $2^{\circ}$ edición, Barcelona: Ariel, 1991.

BUSTOS, Miguel, "Bien jurídico y sanción penal en el delito de omisión del deber de socorro", Foro. Revista de ciencias jurídicas y sociales, V. 15, № 2, pp. 157-183, en: https://revistas.ucm.es/index.php/FORO/issue/view/2354/showToc [visitado el 20/12/2017].

BUSTOS, Miguel, "La pluralidad de sujetos en el delito de omisión del deber de socorro: algunas cuestiones dogmáticas", Revista Jurídica Universidad Autónoma de Madrid, Año 2012, $\quad \mathrm{N}^{\circ}$ 25, pp. 49-69, en: https://revistas.uam.es/revistajuridica/article/view/5964 [visitado el 20/12/2017].

CARINGELLA, Francesco; DE PALMA, Michele; FARINI, Sara; TRINCI, Alessandro, Manuale di Diritto Penale, Parte Speciale, $6^{\circ}$ edizione, Roma: Dike Giuridica, 2016.

COCA, Ivó, "Entre la responsabilidad y la solidaridad. El estado de necesidad defensivo", Indret: Revista para el Análisis del Derecho, Año 2011, № 1, A. 18, pp. 1-40, en: http://www.indret.com/pdf/789.pdf [visitado el 19/06/2017].

DOPICO, Jacobo, "Omisión de socorro tras accidente fortuito. La imputación de sucesos lesivos a conductas licitas", Anuario de Derecho Penal y Ciencias Penales, Año 2002, $\quad$ pp. 235-284, en: https://www.boe.es/publicaciones/anuarios_derecho/anuario.php?id=P_2002_ANU ARIO_DE_DERECHO_PENAL_Y_CIENCIAS_PENALES [visitado el 20/12/2017].

ETCHEBERRY, Alfredo, Derecho Penal, T. IV, $3^{\circ}$ edición, Santiago: Editorial Jurídica de Chile, 1997.

FALCONE, Diego, "El delito de negativa injustificada de un conductor a someterse a los exámenes de detección de alcohol o sustancias estupefacientes o psicotrópicas", Revista de Derecho de la Pontifica Universidad Católica de Valparaíso, V. 46, N ${ }^{\circ}$ 1, pp. 143-169, en: http://www.scielo.cl/pdf/rdpucv/n44/a05.pdf [visitado el 02/04/2017].

FARALDO, Patricia, “Omisión del deber de socorro. Especial referencia a la negativa al tratamiento médico", en: SANZ, Francisco y GÓMEZ, José María (directores), Lecciones de Derecho Sanitario, Coruña: Universidade da Coruña, 1999, pp. 519554. 
Polit. crim. Vol. 13, № 26 (Diciembre 2018) Art. 9, pp. 1003-1026.

[http://www.politicacriminal.cl/Vol_13/n_26/Vol13N26A9.pdf]

FRISCH, Wolfgang, "Derecho penal y solidaridad", Indret: Revista para el Análisis del Derecho, Año 2016, N 4, A. 15, pp. 1-24, en: http://www.indret.com/pdf/1255.pdf [visitado el 02/03/2017].

FRISCH, Wolfgang, Estudios sobre Imputación Objetiva, Santiago: Thomson Reuters, 2012.

GÓMEZ, Víctor, "Omisión del deber de socorro, comisión por omisión y seguridad en el tráfico", en: MIR, Santiago (director) y CARDENAL, Sergi (coordinador), Seguridad vial y Derecho Penal, Valencia: Tirant lo Blanch, 2008, pp. 283-322.

GÓMEZ, Víctor, "Delitos de posición y delitos con elementos meramente tipificadores. Nuevas bases para una distinción necesaria", Revista Electrónica de Ciencia Penal y Criminología, Año 2012, $\mathrm{N}^{\circ}$ 14, pp. 1-29, en: http://criminet.ugr.es/recpc/14/recpc14-01.pdf [visitado el 15/12/2017].

HERNÁNDEZ, Héctor, "El problema de la "causalidad general" en el derecho penal chileno (con ocasión del art. 232 del Anteproyecto de Nuevo Código Penal)", Política Criminal, V. 1, $\quad \mathrm{N}^{\circ} 1, \quad$ A.7, pp. 1-33, en http://www.politicacriminal.cl/n_01/pdf_01/a_7.pdf [visitado el 22/04/2017].

HUERTA, Susana, "Injerencia y art. 489 bis, $3^{\circ}$ CP.", Anuario de Derecho Penal y Ciencias Penales, Año 1985, $\mathrm{N}^{\circ}$ 1, pp. 37-59, en: https://www.boe.es/publicaciones/anuarios_derecho/anuario.php?id=P_1985_ANU ARIO_DE_DERECHO_PENAL_Y_CIENCIAS_PENALES [visitado el 22/12/2017].

JAKOBS, Günther, Derecho penal. Parte general. Fundamentos y teoría de la imputación, $2^{\circ}$ edición, Trad. CUELLO, Joaquín; SERRANO, José Luis, Madrid: Marcial Pons, 1997.

KUHLEN, Lothar, "Características, problemas dogmáticos e importancia práctica del derecho penal alemán de circulación vial", Indret: Revista para el Análisis del Derecho, Año 2013, $\mathrm{N}^{\circ} \quad 2, \quad$ A. 13, pp. 1-29, en: http://www.indret.com/pdf/968_kuhlen.pdf [visitado el 06/01/2018].

LEPIN, Cristián, "Los nuevos principios del derecho de familia", Revista Chilena de Derecho Privado, Año 2014, $\mathrm{N}^{\circ}$ 23, pp. 9-55, en: http://www.scielo.cl/scielo.php?script=sci_arttext\&pid=S071880722014000200001 [visitado el 01/01/2018].

MANTOVANI, Ferrando, Diritto Penale, Parte Speciale, $6^{\circ}$ edizione, Milano: Wolters Kluwer, 2016.

MARINUCCI, Giorgio; DOLCINI, Emilio, Manuale di Diritto Penale, Parte Generale, $6^{\circ}$ edizione, Milano: Giuffrè, 2017.

MATUS, Jean Pierre; RAMÍREZ, María Cecilia, Manual de Derecho Penal Chileno, Parte Especial, Valencia: Tirant lo Blanch, 2017.

MATUS, Jean Pierre, "Ley Emilia", Revista Doctrina y Jurisprudencia Penal, Año 5, edición especial, pp. 101-113.

MOLINA, Concepción, "El artículo 195.3 del código penal de 1995; problemas de aplicación”, Revista de Derecho Penal y Criminología, Año 1999, N 4, pp. 555580.

MUÑOZ CONDE, Francisco, Derecho Penal, Parte Especial, $15^{\circ}$ edición, Valencia: Tirant lo Blanch, 2004. 
ESCOBAR, Javier. "Sujeto activo del delito de omisión de auxilio en accidentes de tránsito".

NAVAS, Iván, "Acción y omisión en infracción de deberes negativos en Derecho penal”, Politica Criminal, V. 10, $\mathrm{N}^{\circ}$ 20, pp. 678-693, en: http://www.politicacriminal.cl/Vol_10/n_20/Vol10N20A8.pdf [visitado el 29/03/2017].

OBANDO, Iván, "El derecho a la seguridad social en el constitucionalismo chileno: Un continente en busca de su contenido", Revista de Estudios Constitucionales, Año 2012, $\quad N^{\circ} \quad 1, \quad$ pp. 289-338, en: http://www.scielo.cl/scielo.php?script=sci_arttext\&pid=S0718$\underline{52002012000100008}$ [visitado el 01/01/2018].

OSSANDON, Magdalena, "Delitos especiales y de infracción de deber en el Anteproyecto de Código Penal", en Política Criminal, Año 2006, $\mathrm{N}^{\circ} 1$, A. 4, pp. 1-22, en: http://www.politicacriminal.cl/n_01/pdf_01/a_4.pdf [visitado el 02/01/2018].

RAGUÉS, Ramón, "Proceso al buen samaritano. Acciones de salvamento y responsabilidad por daños", Indret: Revista para el Análisis del Derecho, Año 2001, N² 2, A. 2, pp. 1-12, en: http://www.indret.com/pdf/049_es.pdf [visitado el 01/01/2018].

ROBLES, Ricardo, "Deberes negativos y positivos en Derecho penal", Indret: Revista para el Análisis del Derecho, Año 2013, $\mathrm{N}^{\circ}$ 4, A. 12, pp. 1-21, en: http://www.indret.com/code/getPdf.php?id=1699\&pdf=1008.pdf [visitado el 24/08/2017].

RODRÍGUEZ, Luis, “Autoría y participación en el delito de producción de material pornográfico infanto-juvenil", Revista de Derecho de la Pontifica Universidad Católica de Valparaíso, V. 45, $\mathrm{N}^{\circ}$ 2, pp. 131-150, en: http://www.rdpucv.cl/index.php/rderecho/article/view/1065/900 [visitado el 21/08/2017].

ROXIN, Claus, Derecho Penal, Parte General, T. I, Trad. LUZÓN PEÑA, Diego-Manuel; DÍAZ Y GARCÍA CONLLEDO, Miguel; DE VICENTE REMESAL, Javier, Madrid: Civitas, 1997.

ROXIN, Claus, Derecho Penal, Parte General, T. II, Trad. LUZÓN PEÑA, Diego-Manuel; PAREDES CASTAÑON, José Manuel; DÍAZ Y GARCÍA CONLLEDO, Miguel; DE VICENTE REMESAL, Javier, Madrid: Thomson Reuters-Civitas, 2014.

SILVA SÁNCHEZ, Jesús María, "Problemas del tipo de omisión del deber de socorro (Comentario a la STS de 27 de abril de 1987)", Anuario de Derecho Penal y Ciencias Penales, Año 1987, $\mathrm{N}^{\circ}$ 2, pp. 561-574, en: https://www.boe.es/publicaciones/anuarios_derecho/abrir_pdf.php?id=ANU-P$1988-$

20056100574_ANUARIO_DE_DERECHO_PENAL_Y_CIENCIAS_PENALES_C omentarios_a_la_jurisprudencia_del_Tribunal_Supremo,_Secci\%F3n_dirigida_por_ Santiago_Mir_Puig:_Problemas_del_tipo_de_omisi\%F3n_del_deber_de_socorro_( Comentario_a_la_STS_de_27_de_abril_de_1987,_ponente_Sr._Diaz_Palos) [visitado el 30/08/2017].

TORÍO, Ángel, “Aspectos de la omisión especial de socorro", Anuario de Derecho Penal y Ciencias Penales, Año 1967, $\mathrm{N}^{\circ}$ 1-2, pp. 581-602, en: https://www.boe.es/publicaciones/anuarios_derecho/anuario.php?id=P_1967_ANU ARIO_DE_DERECHO_PENAL_Y_CIENCIAS_PENALES [visitado el 12/04/2017]. 
Polít. crim. Vol. 13, № 26 (Diciembre 2018) Art. 9, pp. 1003-1026.

[http://www.politicacriminal.cl/Vol_13/n_26/Vol13N26A9.pdf]

VALENZUELA, Jonatan, "La narrativa del deber de ayudar a otro: Samaritanos, héroes y superhéroes", Revista Ius et Praxis, Año $\mathrm{N}^{\circ}$ 20, $\mathrm{N}^{\circ}$ 2, pp. 555-574, en: http://www.scielo.cl/pdf/iusetp/v20n2/art17.pdf [visitado el 01/01/2018].

VAN WEEZEL, Alex, "Solidaridad en el tráfico motorizado. El delito de omisión de auxilio en caso de accidente", Revista Doctrina y Jurisprudencia Penal, Año 5, edición especial, pp. 191-204.

VIDAL, Ernesto, "Sobre los derechos de solidaridad. Del Estado liberal al social y democrático de Derecho", Anuario de Filosofía del Derecho, Año 1993, № 10, pp. $89-110$, en: https://www.boe.es/publicaciones/anuarios_derecho/anuario.php?id=F_1993_ANU ARIO_DE_FILOSOF\%CDA_DEL_DERECHO [visitado el 01/01/2018].

VIVES, Tomás; ORTS, Enrique; CARBONELL, Juan Carlos; GONZÁLEZ, José Luis; MARTÍNEZ-BUJÁN, Carlos, Derecho Penal, Parte Especial, $3^{\circ}$ edición, Valencia: Tirant lo Blanch, 2010.

WILENMANN, Javier, "El fundamento del estado de necesidad justificante en el derecho penal chileno. Al mismo tiempo, introducción al problema", Revista de Derecho Universidad Austral, V. XXVII, $\mathrm{N}^{\circ} 1$, pp. 213-244, en: http://www.scielo.cl/pdf/revider/v27n1/art10.pdf [visitado el 19/06/2017]. 